\title{
Explore Jordanian Mathematics Teacher's Perception of Their Professional Needs Related to Mathematical Proficiency
}

\author{
Khaled Ahmed Aqeel Alzubi
}

\section{ARTICLE INFO}

\section{Article History:}

Received 03.03.2020

Received in revised form

09.12.2020

Accepted

Available online 01.04.2021

\begin{abstract}
Mathematically proficiency as being described it by five strands: conceptual understanding, procedural fluency, strategic competency, adaptive reasoning(National Research Council, 2001), and. The purpose of this study is to Jordanian mathematics teacher's perception of their professional needs Related to the five Strands of Mathematical Proficiency and to search for the effect of teachers demographic factors on their perceived needs. Participants included (171) teachers with varying qualifications and years of experience teaching at multiple grade levels schools in Jordan. The study uses a 35 -item questionnaire to evaluate teachers professional development needs within five Strands of Mathematical Proficiency. The results offer more insight into mathematics teachers' most essential needs in terms of specific knowledge and experience within different categories. This information aids in planning professional development programs and workshops that will meet teachers' needs.
\end{abstract}

C IJERE. All rights reserved

Keywords:

Jordanian mathematics teachers, professional development needs, five strands of mathematical proficiency.

\section{INTRODUCTION}

Over the past few decades, there has been a worldwide increase in the need for teachers' professional development (TPD) (Eyong, Ugada \& Aminu, 2020; Gürer, 2019; Loucks-Horsley \& Matsumoto, 1999; Villegas-Reimers, 2003;). The reason for this increase in TPD is based on the idea that the teacher is a vital person in the teaching and learning process, one who provides information, explains concepts and skills, gives examples, assesses student ability, and provides feedback to support the learning process. Therefore, teachers are the key factor in improving instruction and student learning in the mathematics classroom (Hiebert et al., 1997). Mundry (2005) pointed out the importance of using research-based methods to search for teacher's needs. Shriki and Lavy (2011) addressed the importance of conducting professional development programs that meet teachers needs so that they will be more eager to attend such programs and the teachers professional development will maximize its impact on teachers development, while other researchers mention the need for teachers not only to possess mathematics content knowledge but also to develop effective ways of teaching that help students master mathematics learning (Anshori \& Suwidiyanti, 2020; Ball et al., 2008; Bencherab \& Maskari, 2021; Hariyani, Ahmad \& Marsitin, 2021; Hill \& Ball, 2004;Vural \& Vural, 2021). Teachers professional development is one of the basic elements that aid teachers in building new pedagogical content knowledge and developing their expertise and practice in their classes, ultimately leading to enhanced student learning (Ball, Thames, \& Phelps, 2008; Kaiser et al., 2017; Wood et al., 2011).

\section{Contribution to the literature}

Researchers can use this instrument to search for teachers perceptions of their professional development needs. This current study aims to search for Jordanian teachers needs related to all five strands of mathematical proficiency. The developed research instrument demonstrated high validity and reliability across the strands of mathematical proficiency. Researchers can develop this instrument for use as a qualitative research tool to examine mathematics teacher's needs. The five strands of mathematical proficiency. are conceptual understanding, procedural fluency, strategic competency, adaptive reasoning, and productive disposition. One of the most important aspects of this concept is that "the five strands are interwoven and interdependent in the development of proficiency in mathematics" (NRC, 2001, p. 116).

As described by the five strands developed by the National Research Council, mathematics is commonly viewed as an essential subject throughout the duration of most students' school lives. As a result of the efforts of mathematicians and curriculum developers during the twentieth century, the concept of 
Mathematical Proficiency has emerged (NRC, 2001), for example. According to the NRC (2001), these strands of mathematical proficiency (SMP) comprise all aspects required for any student to learn mathematics successfully. The purpose of this study is to search for Jordanian mathematics teachers perceptions of professional development needs related to the five strands of mathematical proficiency, as well as identify how the teachers demographic factors affect these perceived needs. The five SMP will serve to frame the current study. They will inform the design of the research instrument, as well as the data collection, analysis, and interpretation processes involved in the current study. The following section reviews the literature to give background information and to build a credible theoretical context by defining the strands of mathematical proficiency and relating them to the professional instructional needs of teachers. There are many studies in the mathematical proficiency. In the current study, two aspects are examined. The first body concentrates on i effective mathematics instruction related to the SMP. The second studies on the needs of mathematics teachers and the role of teachers demographic factors that may affect their needs.

\section{The Strands of Mathematical Proficiency}

A review of the literature demonstrates the Strands of mathematical proficiency refers to the "integrated and functional grasp of mathematical ideas", which "enables them learn new ideas by connecting those ideas to what they already know." A few of the benefits of building conceptual understanding are that it supports retention, and prevents common errors. (NRC, 2001, p. 116). The following portion of the surveyed literature provides a review of previous research that addresses the identification of Strands of Mathematical Proficiency and related studies that focus on required teaching skills related to these strands.

Conceptual understanding is the first strand of mathematical proficiency refers to the "integrated and functional grasp of mathematical ideas", which "enables them [students] to learn new ideas by connecting those ideas to what they already know." A few of the benefits of building conceptual understanding are that it supports retention, and prevents common errors. (NRC, 2001, p. 116). Shriki and Patkin (2016) addressed the importance of teachers knowing how to develop a student's ability to represent their mathematical ideas. Davis and Simmt (2006) addressed the need for mathematics teachers to know how concepts are presented and elaborated through the curriculum. They also pointed out that finding vocabulary, images, and algorithms play an important role in developing student understanding of mathematical concepts. Hence, teachers must be adept at 'translating' among available symbol systems and recognizing when they are engaging in such translations.

Procedural fluency is the second strand of mathematical proficiency refers to the skill in carrying out procedures flexibly, accurately, efficiently, and appropriately. Mental gymnastics- Flexibility with number (NRC, 2001). Strategic competence is the third strand of mathematical proficiency refers to the ability to formulate, represent, and solve mathematical problems(NRC, 2001, p. 116). This step reflects students' understanding of the problem and helps them develop appropriate techniques for a solution. Expert problem solvers can form mental representations, detect mathematical relationships, and develop novel solution techniques such as diagram creation, methods of trial and error, table construction, list creation, logical reasoning, pattern finding, or working retrospectively in a flexible way (NCTM, 2000; Common Core State Standards Initiative [CCSSI], 2010; Australian Curriculum and Assessment Reporting Authority [ACARA], 2014).

Adaptive reasoning is the fourth strand of mathematical proficiency refers to the capacity for logical thought, reflection, explanation, and justification.(NRC, 2001, p. 116). Shriki and Patkin (2016) point out that teachers need basic teaching skills to develop students' capabilities of presenting mathematical arguments and justifications, improving their mathematical thinking skills, and furthering their reflective abilities. Productive disposition is the fifth strand of mathematical proficiency refers to is the inclination to see mathematics as sensible, useful, and worthwhile, coupled with a belief in diligence and one's own efficacy. (NRC, 2001, p. 116). Several researchers have addressed the importance of teacher ability in building positive attitudes towards mathematics learning (Fang, 2012; Shriki \& Lavy, 2011; Shriki \& Patkin, 2016). Based on the above description of each strand of mathematical proficiency, the research instrument was developed by constructing the items of the questionnaire and distributing them among the five Strands of Mathematical Proficiency within the data analysis process. 


\section{Mathematics Teachers Needs and Some Related Factors}

In order to present previous research the needs of mathematics teachers, the collected studies were reviewed and classified according to themes related to the Strands of Mathematical Proficiency. Of equal importance is the teachers need to interact with his or her students (Shriki \& Lavy, 2011) to build positive attitudes towards the learning of mathematics; these may reflect productive disposition (Fang, 2012). In the same domain, Shriki and Patkin (2016) examined elementary mathematics teachers perceptions of their professional needs and examined whether a teachers needs changed based on their academic qualifications and the age group taught. The study sample was composed of 84 teachers who were interviewed and responded to a questionnaire. Results showed that the main needs are strengthening teacher knowledge and ability to deal with emotional aspects that relate to students' learning of mathematics. The same results are supported by Fang (2012), who showed that teachers needs in building confidence in teaching mathematics and establishing positive attitudes towards mathematics learning in their classrooms reflect needs related to productive disposition.

Teacher experience as one of the factors that may affect teacher needs. Results of the study findings were reported by Superfine and Li (2014), who designed and implemented a model for the professional development for mathematics teachers who teach content courses through a two-year project. The topics of the project's workshops incorporated six dimensions based on the analysis of teacher and educator practices and needs of teachers. Mapping between the representation and the formulating and revising of mathematical definitions were two of the dimensions that reflect teachers needs in acquiring skills related to conceptual understanding. Similar found that the most relevant needs were teachers development of their mathematical knowledge and the acquisition of knowledge that can help them lead their students towards the understanding of mathematical concepts. Furthermore, Shriki and Lavy (2011) demonstrated that the second most relevant need was knowledge on student learning; teachers must know how students understand mathematics, how they perceive various concepts, and how they construct their mathematical knowledge.

Some studies have addressed teachers need to acquire different teaching skills or knowledge that may enhance students' conceptual understanding (Fang, 2012; Superfine \& Li, 2014; Polly, 2011; Shriki \& Lavy, 2011). More specifically, According to Polly (2011), who examined the impact of the development of technological pedagogical content knowledge of two mathematics teachers after their participation in a learner-centered professional development project, technology may not necessarily assist in this. Although the project concentrated on the use of technology in the mathematics classroom, results of the professional development demonstrated that students' conceptual understanding in mathematics was not improved. Fang (2012) search for the needs of high school mathematics teachers regarding mathematics professional literacy through quantitative and qualitative research. Results showed there is a need to develop teachers skills in using mathematical language and symbols, developing spatial visualization, and acquiring knowledge of common core mathematical concepts and ideas that indicate needs related to conceptual understanding. This indicates that there is still a need to develop teaching skills to enhance students' conceptual understanding. In relation to this stand, Shriki and Lavy (2011).

Other studies search for teachers needs for the development of skills related to mathematical literacy. In turn, this demonstrated teachers need for their students to acquire procedural fluency (Fang, 2012; Evans 2012; Superfine \& Li, 2014). In particular, Fang (2012) demonstrated that teachers skill in performing mathematical operations is one of the most important needs. Evans (2012) found that middle and high school mathematics teachers have poor literacy skills. In relation to this strand, Superfine and Li (2014) demonstrated pre-service elementary teachers needs in analysis of student errors, as well as performing multiplication and division operations on fractions.

Various studies have suggested there is a need for teachers to develop their students' adaptive reasoning skills, such as higher-level thinking skills (Polly, 2011) and the ability to overcome difficulties associated with mathematical justifications and proofs (Superfine \& Li, 2014). the researchers (Steele \& Rogers, 2012) conducted a study to search for the relationship between mathematical knowledge for teaching and teaching practice in reasoning and proofing. The study used a qualitative research approach by conducting observations and clinical assessments for two secondary mathematics teachers who had varying 
degrees of experience, prior knowledge, and school settings. Despite these differences, the results indicated that using Mathematics Knowledge for Teaching (MKT) for examining and assessing classroom practice provides a deeper and more innovative framework for the investigation. Findings of the study also found that student levels of ability to communicate mathematical knowledge is a key mediating factor between MKT and the opportunity to learn. In the same study, Steele and Rogers (2012) found that teachers have difficulties with proofs and they often prefer to follow empirical arguments rather than deductive proofs, as they view the former as easier than the latter.

Other researchers highlighted the need for teachers to master skills that could develop their students' problem-solving skills, which may match their needs related to strategic competence (Evans, 2012, 2014; Fang, 2012; Superfine \& Li, 2014). Fang's (2012) results demonstrated that the competencies of problem solving and applying multiple strategies to solve different kinds of mathematical problems match the strategic competence strand and are the most important skills. Evans (2012) found that middle and high school mathematics teachers who participated in an alternative certificate program had significant improvement in their problem-solving abilities. However, the study also found that although there was improvement in problem-solving abilities, these skills were still generally weak because of teachers failure to start on a problem, poor literacy skills, and a lack of time or effort working on their mathematical problems. In another study, Evans (2014) argued that one of the best ways to help students acquire better content understanding is by providing them with the opportunity to learn through problem solving and inquiry learning, which both include critical thinking.

Although a variety of mathematical teaching competencies were examined in previous studies that reflect the the Strands of Mathematical Proficiency. to some extent, the innovation of this current study is that it aims to search for teachers needs

\section{Related to all Five Strands of MathematicalTeacher Proficiency(STM)}

A review of the literature demonstrates the effect of teacher's characteristics, such as teaching experience, educational background, and age group taught on perceptions of teacher's needs. Shriki and Patkin (2016). Results of the study demonstrated that more experienced teachers perceived fewer professional needs. Findings of the study also showed low significance of teachers academic education and age group taught. In the same context, Evans (2014) pointed out that teachers with less experience were not well prepared in the content and pedagogy required to teach mathematics successfully when compared with experienced teachers.

Shriki and Lavy (2011) found that perceived needs differ based on years of teaching experience. Their findings showed that new teachers perceived needs in developing their knowledge to gain self-confidence, whereas more experienced teachers perceived needs in developing teaching skills to influence student learning. The study also showed that highly experienced teachers perceived needs in developing their knowledge to satisfy their curiosity. In another study, the role of teacher qualifications and grade level taught were search ford by. In the same context, Fang (2012) examined the role of demographic data such as educational background and teaching experience. Results of the study demonstrated that although demographic variables have little or no effect on teachers needs in terms of rating perceived importance, teaching experience has a significant effect on teachers needs in terms of perceived level of mastery in specific domains.

Overall, review of the literature showed that mathematics teachers needs at various grade levels have been well investigated. Previous studies have examined teachers needs at the elementary level (Shriki \& Patkin, 2016), the secondary level (Evans, 2012, 2014; Fang, 2012; Steele \& Rogers, 2012), and the university level (Superfine \& Li, 2014). This current study considers the grade level taught (basic and secondary) as one of the factors to be examined in exploring whether teachers needs differ.

In light of these previous studies, the current study aims to search for the effect of teachers demographic factors, such as qualifications, grade level taught, and years of teaching experience on their perceived needs.

\section{Background and Rationale}


Jordanian students have shown low levels of achievement on international mathematics tests such as TIMSS ( 2012, 2015,2019), National Center for Education Statistics (2012, 2015,2019), and PISA (2012), this study aims to Jordanian mathematics teacher's perception of their professional needs Related to the five Strands of Mathematical Proficiency. Applying such research is of significant importance as part of the assessment of teachers professional development needs, with special consideration of the five strands of mathematical proficiency: conceptual understanding, procedural fluency, strategic competency, adaptive reasoning, and productive disposition. The study provides a theoretical framework for designing a valid and reliable research instrument for measuring and identifying teachers needs related to the SMP. Results of the study will inform researchers, mathematicians, and educators about current needs and direct them to future professional development programs that meet teacher's needs. The study also investigates the effect of teachers demographic factors that may affect their perceived needs. Results and recommendations of the study will guide researchers toward future studies in terms of significant strands and factors. this may improve their instructional practices and indirectly enhance students' learning.

\section{Research Questions}

The study aimed to answer the following two questions:

1-To what extent do to Jordanian mathematics teacher's perception of their professional needs Related to the five Strands of Mathematical Proficiency?

2-Are there any statistically significant differences in perceptions of teachers needs related to the effect of teachers qualifications, grade level taught, and years of teaching experience?

\section{METHODOLOGY AND METHODS}

\section{Research Design}

The study used a quantitative research design using a survey method. A descriptive survey research design was implemented that involved collection of quantitative data to answer the two key research questions. The survey design suits the current study, as the accessible population consisted of a total of (590) Jordanian mathematics teacher, (250) male, (240) female across basic (240), and (102) secondary stages in Jerash Governorate schools in Jordan. The sample of the study consisted of (171) teachers (100) male, (71) female across basic (120), and (51) secondary stages in Jerash Governorate schools in Jordan who were selected randomly and represented $28.9 \%$ of all government school teachers currently teaching mathematics. This survey design (questionnaire) enables quantitative descriptions to represent perceptions and views in a population by studying a sample selected within the population (Creswell, 2014).

\section{Instruments}

To search for to what extent do Jordanian mathematics teacher's perception of their professional needs Related to the five Strands of Mathematical Proficiency, a survey questionnaire was developed by the researcher. The researcher used a comprehensive review of the literature to inform the design of the questionnaire. Following are some examples related to the five SMP: and item a27 states "Developing students' ability in forming connections between relations in mathematics" and item a20 reads "Teaching by using multiple mathematical representation's ". These items were designed based on NRC (2001) and NCTM (2000), which assert that teachers pedagogical knowledge on using multiple mathematical representations and making connections between mathematical ideas are essential skills for developing students' conceptual understanding. Item a14, "Developing students' skills in identifying appropriate procedures," and item a19, "Teaching mental operations and strategies," were constructed based on work by Fuson (1990) and Hiebert et al. (1997), who argued that procedural fluency requires careful instruction to help students achieve different computational skills either by using pencil and paper, conducting mental operations, using calculators or computers, or even giving estimated solutions. Item a10, "Developing students' skills in representing mathematical problems," and item a17, "Developing students' skills in problem-solving strategies," were designed based on CCSSI (2010) and ACARA (2014), which mentioned that strategic competence requires careful instruction to help students form mental representations, detect mathematical relationships, and develop novel solutions and techniques in a flexible way. Regarding adaptive reasoning, item a11, "Identifying mathematical thinking skills," was designed based on Shriki and 
Patkin (2016), who pointed out that teachers should achieve basic teaching skills for developing students' mathematical thinking ability. In addition, item a32, "Enhancing mathematical proof for students," was built based on the NRC (2001), which asserted that teachers are responsible for developing the adaptive reasoning strand for their students by developing their teaching skills in conducting mathematical proofs. Items related to productive disposition, such as a24, "Enhancing students' belief in one's own efficacy," were also designed based on the NRC (2001), which argued that productive disposition refers to the tendency to make sense in mathematics and to see oneself as an effective learner and doer of mathematics. Item a28, "Building positive attitudes towards mathematics," was designed based on Fang (2012) and Shriki and Lavy (2011), who addressed the importance of teachers abilities to build positive attitudes and emotional aspects towards mathematics learning. The questionnaire consisted of two sections. The first section included demographic information such as gender, grade level taught, teachers qualifications, and years of teaching experience. The second section consisted of 35 Likert scale items. The 35 items were rated as follows: $4=$ most relevant to my needs, 3 = relevant to my needs, 2 = fairly relevant to my needs, $1=$ less relevant to my needs, $0=$ not relevant to my needs. Questionnaire items were classified into five domains to measure mathematics teachers needs related to the SMP. Table 1 shows the distribution of items in the strands of mathematical proficiency.

Table1: Item distribution related to the strands of mathematical proficiency (SMP)

\begin{tabular}{|c|c|c|c|c|c|c|}
\hline $\begin{array}{l}\text { Strands } \\
\text { mathematical } \\
\text { proficiency }\end{array}$ & of & $\begin{array}{l}\text { Productive } \\
\text { disposition }\end{array}$ & $\begin{array}{l}\text { Adaptiv } \\
\text { e reasoning }\end{array}$ & $\begin{array}{l}\text { Strategic } \\
\text { competence }\end{array}$ & $\begin{array}{l}\text { Procedu } \\
\text { ral fluency }\end{array}$ & $\begin{array}{l}\text { Conceptual } \\
\text { understanding }\end{array}$ \\
\hline $\begin{array}{ll}\text { Items } & \text { related } \\
\text { SMP } & \end{array}$ & to & $22,24,28,34$ & $\begin{array}{l}3,6,9 \\
11, \quad 29,32, \\
33,35\end{array}$ & $\begin{array}{l}5,10,12,15, \\
17,21,\end{array}$ & $\begin{array}{l}4,13,14,18 \\
19,23\end{array}$ & $\begin{array}{r}1,2,7,8, \\
16,20,25,26 \\
27,30,31\end{array}$ \\
\hline
\end{tabular}

\section{Validity and Reliability of the Instrument}

\section{Validity of the research instrument}

The first process was the translation of the questionnaire into Arabic. To ensure the equivalent meaning of the items, translation and back translation were conducted by two experts who are bilingual in Arabic and English. The back-translation process was performed by an independent person who did not see the original version before translating the instrument back to the first language. The researcher then compared the translated and original versions, found where points were not fully aligned, and made changes to reconcile the versions. A second round of translation by the independent person then took place, with this process continuing until the versions were nearly identical. For construct validity, four experts in the area of mathematics education were consulted and asked to provide explicit notes like, "keep as is," or "keep with these changes ...," or "omit because ..." Accordingly, the references were used to support the validation process and went beyond Cronbach's alpha, also supporting the construct validation and the backtranslation processes. Thus, constructive validity was met. Based on the data gained from the pilot study, the correlation between each of the items against the entire scale $(n=35, N=342)$ was calculated and then items with significant correlations at $\mathrm{p}<0.01$ were selected. Results showed that the questionnaire items' correlations ranged between 0.656 and 0.848 with the whole scale and ranged between 0.716 and 0.875 with the strands. For example, the item correlation for a7 was 0.797 with the whole scale and 0.813 within its related strand (conceptual understanding). The item correlation for a24 was 0.834 with the whole scale and 0.875 with its related strand (productive disposition). Table 2 shows some examples of item correlation with its related strand and with the whole scale. 
Table 2: Item correlations with the whole scale and item correlations with the strands

\begin{tabular}{|c|c|c|c|}
\hline Items & SMP & $\begin{array}{c}\text { Item } \\
\text { correlations with the } \\
\text { whole scale }\end{array}$ & $\begin{array}{c}\text { Item } \\
\text { correlations with the } \\
\text { strands }\end{array}$ \\
\hline a7 & $\begin{array}{l}\text { Conceptual } \\
\text { understanding }\end{array}$ & $.797^{* *}$ & $.813^{* *}$ \\
\hline a13 & $\begin{array}{l}\text { Procedural } \\
\text { fluency }\end{array}$ & $.828^{* *}$ & $.865^{* *}$ \\
\hline a21 & $\begin{array}{l}\text { Strategic } \\
\text { competence }\end{array}$ & $.828^{* *}$ & $.850^{* *}$ \\
\hline a32 & $\begin{array}{l}\text { Adaptive } \\
\text { reasoning }\end{array}$ & $.656^{* *}$ & $.716^{* *}$ \\
\hline a24 & $\begin{array}{l}\text { Productive } \\
\text { disposition }\end{array}$ & $.834^{* *}$ & $.875^{* *}$ \\
\hline
\end{tabular}

**Correlation is significant at the 0.01 level (2-tailed)

In addition, correlations between the strands of mathematical proficiency were calculated, and the results showed positive correlations among them. The value of (r) ranged between 0.817 and 0.963 . For example, the correlation between strategic competence and productive disposition was 0.817 , while the correlation between procedural fluency and the whole scale was 0.963 . Previous values of (r) demonstrate that the questionnaire has good validity.

\section{Reliability of the research instrument}

The statistical reliability of the instrument was calculated using Cronbach's alpha coefficient of internal consistency both for the questionnaire as a whole and separately for the five strands. The analyses produced a 0.98 alpha coefficient value for the whole questionnaire, 0.939 value for conceptual understanding, 0.915 value for procedural fluency, 0.908 value for both strategic competence and adaptive reasoning, and 0.873 value for productive disposition, which indicated a satisfactory level of reliability (Robinson, Shaver, \& Wrightsman, 1991). The high-value alpha coefficients suggest that the instrument is suitable to measure mathematics teachers perceptions of professional development needs related to the SMP.

\section{Participants and Data Collection}

The research was conducted during the first semester of the (2019-2020) academic year. The questionnaire was distributed to over 16 basic and secondary schools in Jerash Governorate in Jordan. Participants were 171 teachers (100) male, (71) female across basic (120), and (51) secondary stages in Jerash Governorate schools in Jordan. Qualifications varied from bachelor's degrees (130) to higher diplomas (24) to master's or Ph.D. level (17). Experience ranged from 1-3 years (13), 4-6 years (38), 7-11 years (44), 12-18 years (40), to more than 18 years (36)

Mathematics teachers were also informed about the purpose of the study, asked to respond to the questionnaire, and assured of confidentiality. teachers in the participating schools were asked to volunteer to participate in the study.

\section{Data Analysis}

The study followed a quantitative research approach. Descriptive statistics were utilized via Statistical Packages for Social Sciences (SPSS 15.0). To answer the first research question, means, standard deviations, percentages, and t-tests were used for pre-defined values to identify Jordanian mathematics teacher's perception of their professional needs Related to the five Strands of Mathematical Proficiency.

A comparison was made between the mean score of the responses on the items of the questionnaire, the five strands of mathematical proficiency, and for the whole scale. Additionally, $t$-values were calculated to examine if there were statistically significant differences regarding teachers needs compared with a 
predetermined average value $(=2)$ that lies in the middle of the scale; this is because the scale was a Likerttype scale ranging from 0 to 4 . Teachers responses were classified based on a descriptive rubric (Table 3) which was presented at the beginning of the questionnaire to guide participants in how to respond to the questionnaire items, and to specify operationally their professional development needs related to the SMP

Table 3: Descriptive rubric of teachers' professional development needs related to the SMP

\begin{tabular}{|c|c|c|}
\hline $\begin{array}{l}\text { Teachers' PD } \\
\text { Needs }\end{array}$ & Description & Scale \\
\hline $\begin{array}{l}\text { Most relevant } \\
\text { to my needs }\end{array}$ & $\begin{array}{l}\text { Means that you have no information about this } \\
\text { subject/topic and cannot apply it in the teaching of } \\
\text { mathematics. }\end{array}$ & 4 \\
\hline $\begin{array}{l}\text { Relevant to my } \\
\text { needs }\end{array}$ & $\begin{array}{l}\text { Means that you know little information about this } \\
\text { subject but you cannot apply it in the teaching of } \\
\text { mathematics. }\end{array}$ & 3 \\
\hline $\begin{array}{l}\text { Fairly relevant } \\
\text { to my needs }\end{array}$ & $\begin{array}{l}\text { Means that you have some information about this } \\
\text { subject and have limited experience in its application in the } \\
\text { teaching of mathematics. }\end{array}$ & 2 \\
\hline $\begin{array}{l}\text { Less relevant } \\
\text { to my needs }\end{array}$ & $\begin{array}{l}\text { Means that you have good knowledge about this subject } \\
\text { and good experience in its applications in the teaching of } \\
\text { mathematics. }\end{array}$ & 1 \\
\hline $\begin{array}{l}\text { Not relevant to } \\
\text { my needs (no need) }\end{array}$ & $\begin{array}{l}\text { Means that you have wide knowledge about this subject } \\
\text { and wide experience and skills to apply it in the teaching of } \\
\text { mathematics effectively. }\end{array}$ & 0 \\
\hline
\end{tabular}

The top 3 box scores were also used to better understand and analyze the scale questions by calculating the sum of percentages for the three highest rating points on the scale.

In addition, means, standard deviations, and Analysis of Variance (ANOVA) were calculated to examine if there were any statistically significant differences in teachers perceptions regarding their needs related to the SMP in favor of the effect of teachers qualifications, grade level taught, and years of teaching experience.

\section{RESULTS}

\section{Findings Related to the First Research Question}

The first question of the study examined to what extent Jordanian mathematics teacher's perception of their professional needs Related to the five Strands of Mathematical Proficiency. As shown in Table 4, the overall mean score for the scale. 
Table 4: Means, standard deviations and t-tests of teachers' perceptions regarding their needs

\begin{tabular}{cccccccc}
\hline \begin{tabular}{c} 
One-Sample $\begin{array}{c}\text { Test value }=2 \\
\text { Statistics }\end{array}$ \\
\cline { 2 - 7 }
\end{tabular} & $\mathrm{N}$ & Mean & Std.deviation & $\begin{array}{c}\text { Std.error } \\
\text { mean }\end{array}$ & $\mathrm{T}$ & $\mathrm{f}$ & $\begin{array}{c}\text { Sig.(two } \\
\text { tail) }\end{array}$ \\
\hline $\begin{array}{c}\text { Conceptual } \\
\text { understanding }\end{array}$ & 170 & 2.49 & 9.37 & 0.053 & 9.37 & 69 & 0.000 \\
$\begin{array}{c}\text { Procedural } \\
\text { fluency }\end{array}$ & 171 & 2.45 & 8.42 & 0.054 & 8.42 & 70 & 0.000 \\
$\begin{array}{c}\text { Strategic } \\
\text { competence }\end{array}$ & 171 & 2.47 & 8.54 & 0.055 & 8.54 & 70 & 0.000 \\
$\begin{array}{c}\text { Adaptive } \\
\text { reasoning }\end{array}$ & 171 & 2.56 & 11.10 & 0.051 & 11.10 & 70 & 0.000 \\
$\begin{array}{c}\text { Productive } \\
\text { disposition }\end{array}$ & 170 & 2.60 & 10.32 & 0.059 & 10.32 & 69 & 0.000 \\
$\begin{array}{c}\text { Mathematical } \\
\text { proficiency }\end{array}$ & 170 & 2.52 & 10.05 & 0.052 & 10.05 & 169 & 0.000 \\
\hline
\end{tabular}

was 2.52, suggesting that relevant professional development needs were significantly related to the SMP as a whole and to all the strands of mathematical proficiency in particular.

Results also showed that productive disposition had the highest mean (2.60), followed by adaptive reasoning (2.56) and conceptual understanding (2.49), while the mean score for strategic competence was 2.47 , followed by the lowest mean (2.45) for procedural fluency.

The weighted means for the items of the questionnaire were calculated and classified as follows to specify mathematics teachers needs. Since the scale was a Likert-type that ranged from 0 to 4 through 5 classifications, the range for each classification was calculated by dividing 4 by 5 (equal to 0.80). The limits for each classification were calculated starting from 0.0 , adding 0.80 sequentially, and ending in 4 . Hence, the first classification ranged from 0.00 to 0.80 , the second classification ranged between 0.81 and 1.60 , and so on. This procedure formed the five classifications. Therefore, the weighted mean of teachers responses to the items of the questionnaire were classified based on these limits sequentially as follows: not relevant (0.0$0.80)$, less relevant (0.81-1.60), fairly relevant (1.61-2.40), relevant (2.41-3.20), and most relevant (3.21-4.00). 


\begin{tabular}{|c|c|c|}
\hline $\begin{array}{l}\text { Conceptual understanding (CU) } \\
\text { a1: Identifying the mathematical } \\
\text { concepts included in the mathematical content }\end{array}$ & 1.99 & Fairly Relevant \\
\hline $\begin{array}{l}\text { a2: Applying specific strategies for } \\
\text { teaching mathematical concepts }\end{array}$ & 2.53 & Relevant \\
\hline $\begin{array}{c}\text { a7: Developing } \quad \text { conceptual } \\
\text { understanding for students }\end{array}$ & 2.39 & Fairly Relevant \\
\hline $\begin{array}{ccc}\text { a8: } & \text { Developing } & \text { students' }\end{array}$ & 2.35 & Fairly Relevant \\
\hline $\begin{array}{l}\text { comprehension of mathematical operations } \\
\text { a16: Teaching to amend alternative } \\
\text { concepts }\end{array}$ & 2.62 & Relevant \\
\hline $\begin{array}{l}\text { a20: Teaching by using multiple } \\
\text { mathematical representations }\end{array}$ & 2.63 & Relevant \\
\hline $\begin{array}{l}\text { a25: Measuring student acquisition of } \\
\text { mathematical concepts }\end{array}$ & 2.52 & Relevant \\
\hline $\begin{array}{l}\text { a26: Teaching mathematical concepts } \\
\text { via problem solving }\end{array}$ & 2.54 & Relevant \\
\hline $\begin{array}{l}\text { a27: Developing students' ability in } \\
\text { forming connections between relations in } \\
\text { mathematics }\end{array}$ & 2.5 & Relevant \\
\hline $\begin{array}{l}\text { a30: Making connections between } \\
\text { mathematical concepts and procedures to reach } \\
\text { mathematical generalizations }\end{array}$ & 2.61 & Relevant \\
\hline $\begin{array}{l}\text { a31: Using conceptual maps in } \\
\text { teaching mathematics } \\
\text { Procedural fluency }(\mathbf{P F})\end{array}$ & 2.73 & Relevant \\
\hline $\begin{array}{l}\text { a4: Identifying algorithms and skills } \\
\text { included in the mathematical content }\end{array}$ & 2.27 & Fairly Relevant \\
\hline $\begin{array}{l}\text { a13: } \begin{array}{l}\text { Developing } \\
\text { students' } \\
\text { competencies in carrying out } \\
\text { flexibly in mathematical exercises }\end{array}\end{array}$ & 2.34 & Fairly Relevant \\
\hline $\begin{array}{l}\text { a14: Developing students' skills in } \\
\text { identifying appropriate procedures }\end{array}$ & 2.41 & Relevant \\
\hline $\begin{array}{l}\text { a18: Enhancing students' procedural } \\
\text { fluency in mathematical operations }\end{array}$ & 2.71 & Relevant \\
\hline $\begin{array}{l}\text { a19: Teaching mental operations and } \\
\text { strategies }\end{array}$ & 2.57 & Relevant \\
\hline $\begin{array}{l}\text { a23: Enhancing students' skills in } \\
\text { carrying out procedures accurately } \\
\text { Strategic competence(SA) }\end{array}$ & 2.4 & Fairly Relevant \\
\hline $\begin{array}{l}\text { a5: Developing students' ability in } \\
\text { formulating word problems }\end{array}$ & 2.6 & Relevant \\
\hline $\begin{array}{l}\text { a10: Developing students' skills in } \\
\text { representing mathematical problems }\end{array}$ & 2.47 & Relevant \\
\hline $\begin{array}{l}\text { a12: Teaching problem solving } \\
\text { strategies }\end{array}$ & 2.41 & Relevant \\
\hline $\begin{array}{l}\text { a15: Teaching problem solving } \\
\text { techniques (steps) }\end{array}$ & 2.26 & Fairly Relevant \\
\hline $\begin{array}{l}\text { a17: Developing students' skills in } \\
\text { problem solving strategies }\end{array}$ & 2.53 & Relevant \\
\hline $\begin{array}{l}\text { a21: Enhancing students' skills in } \\
\text { problem solving }\end{array}$ & 2.55 & Relevant \\
\hline $\begin{array}{l}\text { a3: Developing inductive reasoning } \\
\text { for students }\end{array}$ & 2.8 & Relevant \\
\hline $\begin{array}{l}\text { a6: Developing logical thinking for } \\
\text { students }\end{array}$ & 2.55 & Relevant \\
\hline $\begin{array}{l}\text { a9: Developing deductive reasoning } \\
\text { for students }\end{array}$ & 2.5 & Relevant \\
\hline $\begin{array}{c}\text { a11: } \text { Identifying } \text { mathematical } \\
\text { thinking skills }\end{array}$ & 2.44 & Relevant \\
\hline $\begin{array}{l}\text { a29: Modeling mathematical problems } \\
\text { in daily life situations }\end{array}$ & 2.52 & Relevant \\
\hline $\begin{array}{l}\text { a32: Enhancing mathematical proof for } \\
\text { students }\end{array}$ & 2.68 & Relevant \\
\hline $\begin{array}{l}\text { a33: Enhancing students skills in } \\
\text { approximation, estimation, and prediction }\end{array}$ & 2.52 & Relevant \\
\hline $\begin{array}{l}\text { a35: Teaching mathematical patterns } \\
\text { Productive disposition (Pd) }\end{array}$ & 2.47 & Relevant \\
\hline $\begin{array}{l}\text { a22: Enhancing students' habitual } \\
\text { inclination to see mathematics as sensible, } \\
\text { useful, and worthwhile }\end{array}$ & 2.58 & Relevant \\
\hline $\begin{array}{l}\text { a24: Enhancing students' belief in } \\
\text { one's own efficacy }\end{array}$ & 2.56 & Relevant \\
\hline $\begin{array}{l}\text { a28: Building positive attitudes } \\
\text { towards mathematics }\end{array}$ & 2.58 & Relevant \\
\hline $\begin{array}{l}\text { a34: Enhancing students belief in } \\
\text { diligence in learning mathematics }\end{array}$ & 2.68 & Relevant \\
\hline
\end{tabular}


Table 5 presents the findings demonstrating teachers responses towards the items of the questionnaire, reflecting their perceptions on professional development needs related to the SMP.

The results of this study showed that mathematics teachers perceived a need for professional development in all items related to productive disposition and adaptive reasoning, such as "Enhancing students' belief in one's own efficacy" and "Enhancing mathematical proof for students." In addition, they have professional development needs for most of the items belonging to conceptual understanding, such as "Teaching by using multiple mathematical representations," and strategic competence. From the perception of mathematics teachers, needs were also fairly relevant for procedural fluency items such as "Enhancing students' skills in carrying out procedures accurately".

To provide more detail, we reported the survey results in a more informative way by using the top 3 box scores. Table 6 presents the top 3 box scores results by calculating the sum of percentages for the top three highest rating points on the scale, which reflects the percentage of teachers who responded to the items of the questionnaire with "most relevant to my needs", "relevant to my needs" or "fairly relevant to my needs." In addition, Table 6 indicates the ranking of the items of the questionnaire and sorts them relative to the five SMP.

\begin{tabular}{|c|c|c|c|}
\hline Ran & Items & SM & Top \\
\hline \multirow[t]{2}{*}{ king } & & Domain & 3 Box \\
\hline & & & Scores $\%$ \\
\hline 1 & a3: Developing inductive reasoning for students & AR & 57 \\
\hline 2 & a31: Using conceptual maps in teaching mathematics & $\mathrm{CU}$ & 56 \\
\hline 3 & a18: Enhancing students' procedural fluency in mathematical operations & $\mathrm{PF}$ & 55 \\
\hline 4 & a32: Enhancing mathematical proof for students & $\mathrm{AR}$ & 52 \\
\hline 5 & a34: Enhancing students' belief in diligence in learning mathematics & PD & 51 \\
\hline 6 & a20: Teaching by using multiple mathematical representations & $\mathrm{CU}$ & 50 \\
\hline 7 & a28: Building positive attitudes towards mathematics & PD & 49 \\
\hline 8 & a16: Teaching to amend alternative concepts & $\mathrm{CU}$ & 48 \\
\hline \multirow[t]{5}{*}{9} & a5: Developing students' ability in formulating word problems & SC & 48 \\
\hline & a19: Teaching mental operations and strategies & $\mathrm{PF}$ & 48 \\
\hline & $\begin{array}{l}\text { a22: Enhancing students' habitual inclination to see mathematics as sensible, } \\
\text { useful, and worthwhile }\end{array}$ & $\mathrm{PD}$ & 48 \\
\hline & a24: Enhancing students' belief in one's own efficacy & PD & 47 \\
\hline & $\begin{array}{l}\text { a30: Making connections between mathematical concepts and procedures to } \\
\text { reach mathematical generalizations }\end{array}$ & $\mathrm{CU}$ & 47 \\
\hline \multirow[t]{6}{*}{10} & a2: Applying specific strategies for teaching mathematical concepts & $\mathrm{CU}$ & 46 \\
\hline & a17: Developing students' skills in problem solving strategies & SC & 46 \\
\hline & a21: Enhancing students' skills in problem solving & SC & 46 \\
\hline & a6: Developing logical thinking for students & AR & 46 \\
\hline & a9: Developing deductive reasoning for students & AR & 46 \\
\hline & a29: Modelling mathematical problems in daily life situations & AR & 46 \\
\hline \multirow[t]{2}{*}{11} & a33: Enhancing students' skills in approximation, estimation, and prediction & AR & 45 \\
\hline & a35: Teaching mathematical patterns & AR & 45 \\
\hline \multirow[t]{3}{*}{12} & a26: Teaching mathematical concepts via problem solving & $\mathrm{CU}$ & 44 \\
\hline & $\begin{array}{l}\text { a27: Developing students' ability in forming connections between relations in } \\
\text { mathematics }\end{array}$ & $\mathrm{CU}$ & 44 \\
\hline & a10: Developing students' skills in representing mathematical problems & SC & 44 \\
\hline 13 & a25: Measuring student acquisition of mathematical concepts & CU & 43 \\
\hline 14 & a11: Identifying mathematical thinking skills & AR & 42 \\
\hline 14 & a14: Developing students' skills in identifying appropriate procedures & $\mathrm{PF}$ & 42 \\
\hline \multirow[t]{2}{*}{15} & a23: Enhancing students' skills in carrying out procedures accurately & $\mathrm{CU}$ & 42 \\
\hline & a7: Developing conceptual understanding for students & $\mathrm{AR}$ & 40 \\
\hline \multirow[t]{2}{*}{16} & a12: Teaching problem solving strategies & $\mathrm{SC}$ & 40 \\
\hline & $\begin{array}{l}\text { a13: Developing students' competencies in carrying out procedures flexibly } \\
\text { in mathematical exercises }\end{array}$ & $\mathrm{PF}$ & 39 \\
\hline 17 & a8: Developing students' comprehension of mathematical operations & $\mathrm{CU}$ & 37 \\
\hline 18 & a4: Identifying algorithms and skills included in the mathematical content & $\mathrm{PF}$ & 34 \\
\hline 19 & a15: Teaching problem solving techniques (steps) & SC & 33 \\
\hline 20 & $\begin{array}{l}\text { a1: Identifying the mathematical concepts included in the mathematical } \\
\text { content }\end{array}$ & CU & 25 \\
\hline
\end{tabular}

* CU: Conceptual Understanding, PF: Procedural fluency, SC: Strategic Competence, AR: Adaptive reasoning, PD: Productive Disposition

The 35 items are ranked from 1 to 20 (see the far left column of Table 6, where the items with the same percentage have the same rank), according to the importance that the respondents attributed to them. 
Previous analyses (using mean scores and standard deviation) demonstrated that the teachers professional development needs were related to all five SMP, with productive disposition receiving the highest mean score, followed by adaptive reasoning, conceptual understanding, and strategic competence, with the lowest mean for procedural fluency. Table 6 gives more in-depth insights regarding teachers perceptions of the extent to which they need professional development based on their knowledge and experiences that are represented by the items of the questionnaire in relation to each strand of mathematical proficiency.

Based on the descriptive rubric of the rating scale presented in Table 3, the results in Table 6 reflect the

percentage of respondents who perceived that either they have no information about the item's subject/topic and cannot apply it in the teaching of mathematics, or they have little information about this subject but they cannot apply it in the teaching of mathematics, or they have some information about this subject but have limited experience in its application in the teaching of mathematics. In brief, the results of the top 3 box scores show the percentage of perceived professional development needs as demonstrated by the respondents.

The top six items in Table 6 represent the most essential perceived needs, as demonstrated by $50 \%$ or more of the respondents. Item a3 "developing inductive reasoning for students" was ranked first, which relates to the "adaptive reasoning" domain (57\% of the respondents ranked it as "most relevant to my needs", "relevant to my needs" or "fairly relevant to my needs"). At the same time, item a32 "Enhancing mathematical proof for students", which is also associated with the same domain, was ranked fourth. In addition, Table 6 reveals that more than half of the respondents (56\%) perceived professional development needs for "using conceptual maps in teaching mathematics " (a31), and half of them (50\%) perceived professional development needs for "teaching by using multiple mathematical representations" (a20), both associated with the "conceptual understanding" domain. Additional essential needs for more than half of the respondents $(55 \%)$ are associated with the "procedural fluency" domain, with perceived needs for "enhancing students' procedural fluency in mathematical operations" (a18), and "productive disposition" domain corresponding to $51 \%$ of respondents' needs, with perceived needs for "enhancing students' belief in diligence in learning mathematics" (a34).

Table 6 also gives a clear insight into the teachers perceived professional development needs related to the "productive disposition" domain, where all items associated with this strand are ranked in the first top 9, such as "building positive attitudes towards mathematics" (a28), which was ranked seventh (49\%), "enhancing students' habitual inclination to see mathematics as sensible,

Comparing items associated with "conceptual understanding" domain, Table 6 shows that some items have a lower ranking in the first top10, such as "teaching to amend alternative concepts" ranked eighth (a16, $48 \%$ ), "making connections between mathematical concepts and procedures to reach mathematical generalizations" ranked ninth (a30, 47\%), and "applying specific strategies for teaching mathematical concepts" ranked tenth (a2, 46\%). At the same time, some items related to the same domain of "conceptual understanding" have a very low ranking, such as "developing conceptual understanding for students", which is ranked fifteenth $(\mathrm{a} 7,40 \%)$, and "developing students' comprehension of mathematical operations", which is ranked seventeenth (a8, 37\%). Moreover, the last item, in the same domain of "conceptual understanding", shows that a lower percentage of teachers (25\%) perceived professional development needs for developing their skills in "identifying the mathematical concepts included in the mathematical content" (a1).

In addition, Table 6 demonstrates that although some items related to the "adaptive reasoning" domain had higher percentage of perceived needs as demonstrated by the respondents (a3, a32), the majority of the items related to the same domain had a middle-ranking, in that some were ranked tenth $(46 \%)$, such as "developing logical thinking for students" (a6), "developing deductive reasoning for students" (a9), and "modeling mathematical problems in daily life situations" (a29), and others were ranked eleventh (45\%), such as "enhancing students' skills in approximation, estimation, and prediction" (a33) and "teaching mathematical patterns" (a35).

For the "strategic competence" domain, Table 6 reflects a variety of the respondents' needs, ranking eighth, such as "developing students' ability in formulating word problems" (a5, 48\%) and tenth (46\%), such 
as "developing students' skills in problem solving strategies" (a17), and "enhancing students' skills in problem solving" (a21). In contrast, another item received a low ranking Table 6. Top 3 box scores results of teachers responses to the items of the questionnaire, sorted by ranking and SMP domain.

For the "strategic competence" domain, Table 6 reflects a variety of the respondents' needs, ranking eighth, such as "developing students' ability in formulating word problems" (a5, 48\%) and tenth (46\%), such as "developing students' skills in problem solving strategies" (a17), and "enhancing students' skills in problem solving" (a21). In contrast, another item received a low ranking

Table 6 reveals that most items related to the "procedural fluency" domain have the lowest ranking, representing fewer perceived needs for "developing students' competencies in carrying out procedures flexibly in mathematical exercises" (a13, 39\%), which was ranked sixteenth, and for "identifying algorithms and skills included in the mathematical content" (a4,34\%), ranked eighteenth.

\section{Findings Related to the Second Research Question}

The second research question search ford whether there were statistically significant differences in perceptions of mathematics teachers professional development needs related to the SMP, specifically with regard to the effect of demographic variables such as the teachers qualifications, grade level taught, and years of teaching experience.

To examine if there are statistically significant differences related to the effect of the grade level taught, a one-way analysis of variance (ANOVA) was utilized. Mathematics teachers were grouped according to the grade level taught (basic, and secondary). The one-way ANOVA revealed no statistically significant differences related to grade level taught for each SMP in particular or for mathematical proficiency as a whole. For example, for conceptual understanding, the one-way ANOVA revealed no statistically significant difference: $F(2,338)=0.890, p=0.412$. In addition, for total mathematical proficiency, the one-way ANOVA revealed no statistically significant difference: $F(2,338)=0.637, p=0.530$. This result suggests that teachers who teach basic, and secondary grade levels have similar needs.

A one-way ANOVA was also utilized to examine whether there were statistically significant differences related to the effect of teacher qualifications. Mathematics teachers were grouped according to their education levels (bachelor, higher diploma, and master or $\mathrm{PhD}$ ). The one-way ANOVA revealed there were no statistically significant differences related to teachers qualifications for all strands of mathematical proficiency and for mathematical proficiency as a whole. For example, for productive disposition, the oneway ANOVA revealed no statistically significant difference: $F(2,337)=0.80, p=0.45$. In addition, for the total mathematical proficiency, the one-way ANOVA revealed no statistically significant difference: $F(2,337)=$ $0.32, p=0.73$. This result suggests that teachers who have baccalaureate degrees, higher diplomas, or even master-level or doctorate degrees have similar needs.

To examine if there were any statistically significant differences related to the effect of number of years of teaching experience, a one-way ANOVA was utilized. Mathematics teachers were grouped according to years of teaching experience (1-3 years, 4-6 years, 7-11 years, 12-18 years, and more than 18 years). The oneway ANOVA revealed that there were statistically significant differences with a medium effect size (0.04$0.06)$ related to years of teaching experience for all components of SMP: $F(4,335)=3.39, p=0.01$ for conceptual understanding, $\mathrm{F}(4,336)=4.938, \mathrm{p}=0.001$ for procedural fluency, $\mathrm{F}(4,336)=4.678, \mathrm{p}=0.001$ for strategic competence, $F(4,336)=4.049, p=0.003$ for adaptive reasoning, and $F(4,335)=3.609, p=0.007$ for productive disposition. For mathematical proficiency as a whole, the finding was $F(4,335)=4.561, p=0.001$. This result suggests that mathematics teachers needs differ based on their teaching experience.

A post hoc test (Tukey HSD) was utilized to determine exactly where the means differed. The post hoc test revealed that teachers with experience ranging from 4 to 6 years $(p=0.003)$ and from 7 to 11 years $(p=$ 0.012) perceived more professional development needs, with statistically significant differences compared with other teachers with less experience (from 1 to 3 years) or with more experience (more than 18 years), for each strand in particular and for the whole SMP in general. One exception is for teachers with experience from 4 to 6 years, who perceive more needs related to conceptual understanding, with statistically significant differences $(p=0.026)$ when compared with the other groups of mathematics teachers. 
The above results reveal that there were no statistically significant differences among teachers due to teachers qualifications or grade level taught, while statistically significant differences were found in terms of years of teaching experience. To investigate further, we used the top 3 box scores according to teachers qualifications, grade level taught, and years of teaching experience to search for trends or tendencies in each group. The results of the top 3 box scores show some differences regarding the percentage of perceived professional development needs as demonstrated by the respondents of different groups in some domains.

For example, item a3 "developing inductive reasoning for students" was ranked first in terms of perceived needs and relates to the "adaptive reasoning" domain. As shown in Figure 1, the results of the top 3 box scores by grade level taught revealed that the primary teachers perceived more needs (62\%) compared to the other groups, with fewer perceived needs for secondary teachers (52\%). For "using conceptual maps in teaching mathematics primary", which relates to the "conceptual understanding" domain. The results show equivalent perceived needs for primary and preparatory teachers $(61 \%)$, while secondary teachers perceived fewer needs $(48 \%)$.

Figure1 the equivalent perceived needs for teachers in all groups regarding:

Figure 1: Example of TOP 3 BOX SCORES BY GRADE LEVEL TAUGHT

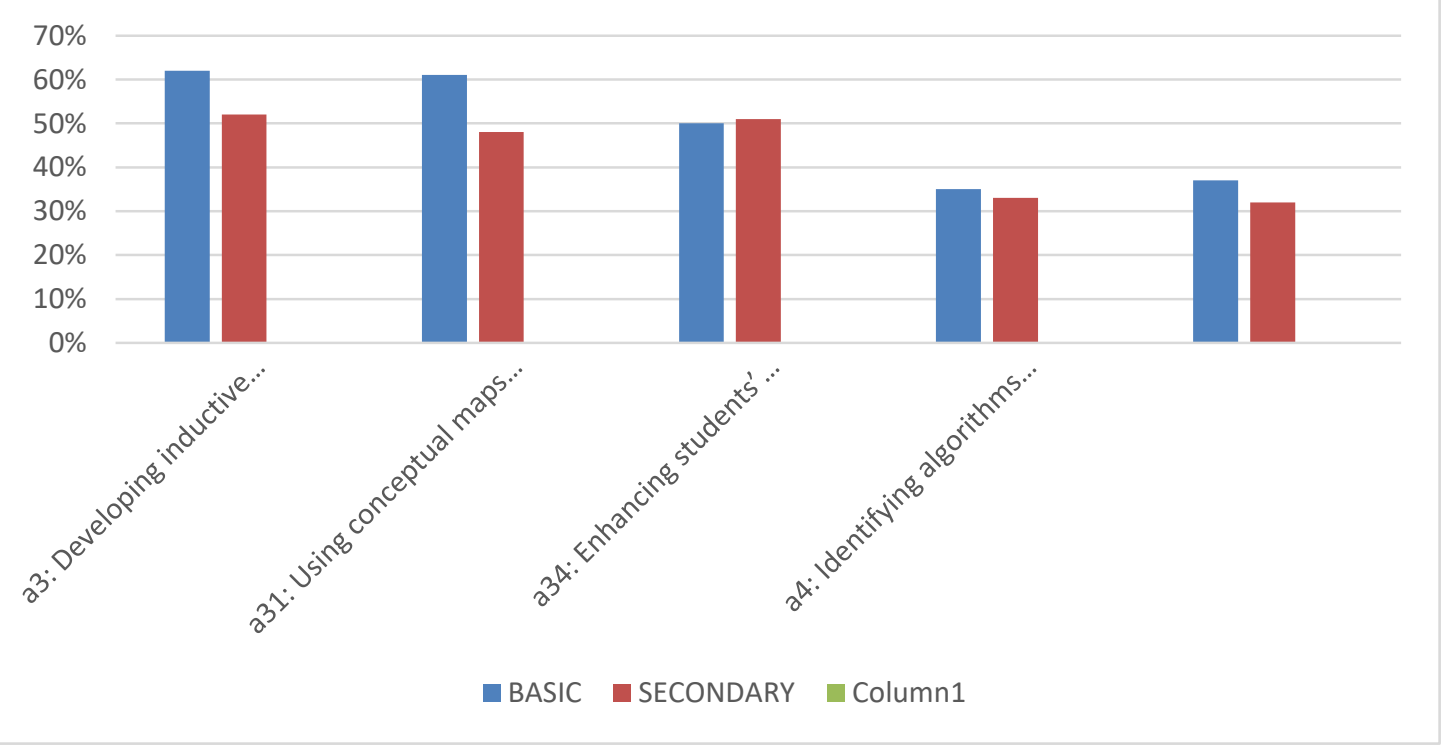

Figure 1 shows the equivalent perceived needs for teachers in all groups regarding "enhancing students' belief in diligence in learning mathematics" in relation to the "productive disposition" domain. For items ranked last, the results show differences in perceived needs between the different groups. For example, as shown in Figure 1, equivalent perceived needs were found for teachers in different groups for "identifying algorithms and skills included in the mathematical content", which relates to the "procedural fluency" domain. In the "strategic competency" domain, teachers needs for "teaching problem solving techniques (steps)" differed between different groups. The results show that preparatory teachers perceived fewer needs (28\%) compared to other groups, with more needs found for primary teachers. 
Figure 2: Teachers qualifications

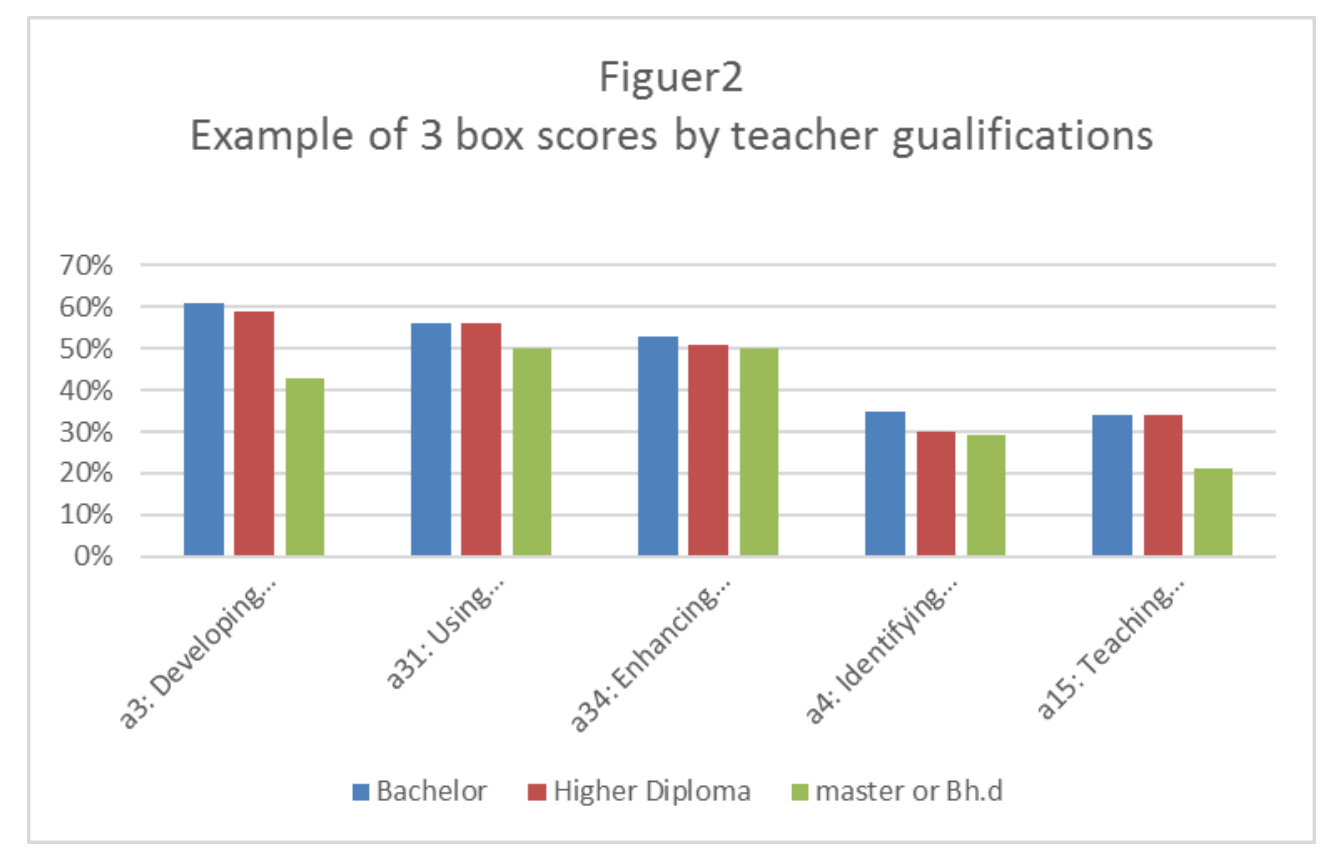

The results from the Top 3 box scores by teachers qualifications also showed different percentages regarding perceived needs in different groups. As shown in Figure 2, in all items related to the different domains, teachers with a master's or Ph.D. qualification perceived fewer professional development needs. For some items, the result showed equivalent perceived needs between teachers who had a bachelor's degree and those who had a post graduate degree, such as their needs regarding "using conceptual maps in teaching mathematics" and "teaching problem solving techniques (step)."

The results of the Top 3 box scores by years of teaching experience also revealed differences regarding teachers perceived needs in different groups. As shown in Figure 3, teachers with more experience perceived fewer needs related to the presented items in all the domains. In addition, the results showed more perceived needs for teachers who had 7-11 years' experience for most items compared to the other groups, such as in "developing inductive reasoning for students", which relates to the "adaptive reasoning" domain. Likewise, those with less experience also showed more perceived needs compared to the more experience groups in the "using conceptual maps in teaching mathematics", which relates to the "conceptual understanding" domain and in the "teaching problem solving techniques (steps)", which relates to the "strategic competence" domain. 


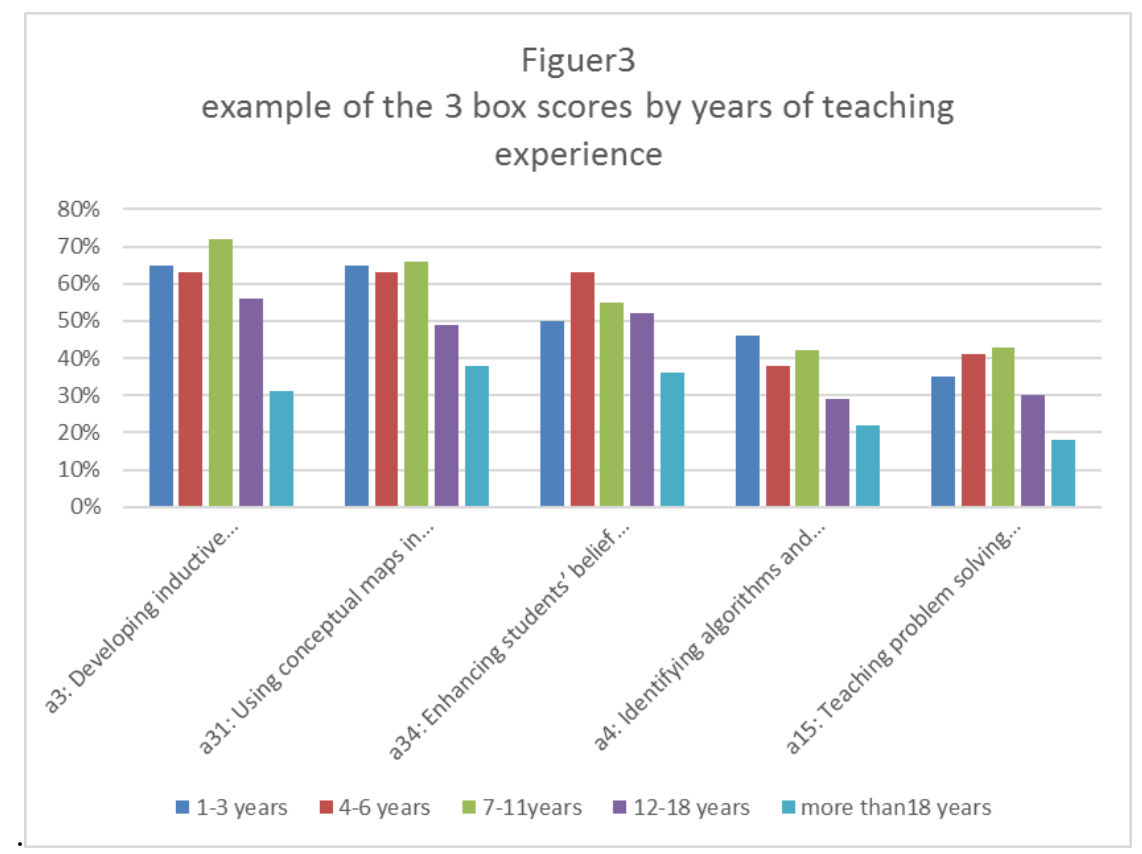

Figure 3 also shows that teachers with 4-6 years of experience had the highest percentage $(63 \%)$ of perceived needs compared to other groups for "enhancing students' belief in diligence in learning mathematics", relating to the "productive disposition" domain. Figure 3 also shows other findings regarding teachers need for "identifying algorithms and skills included in the mathematical content", relating to the "procedural fluency" domain, whereby the highest percentage was for teachers with 1-3 years of teaching experience.

\section{DISCUSSION}

As the review of the literature demonstrated, there is no doubt that investigating teachers perceptions regarding their need for professional development related to SMP is an important issue for educators and researchers, strongly emphasizing the importance of reforming mathematics education programs. In addition, researchers and educators in the field of mathematics education have developed the concept of successful mathematics learning, leading to the concept of mathematical proficiency.

The results of the study found that the overall mean score for the scale was 2.52, representing relevant professional development needs with statistically significant differences related to the SMP as a whole and for all strands of mathematical proficiency. In addition, the mean score for the strands of mathematical proficiency varied between 2.45 and 2.60. Statistically significant differences were found for the different strands of mathematical proficiency, representing slight variation in mathematics teachers' perceived needs for professional development. These results support the importance of current research identifying critical domains for future professional development of mathematics teachers.

The results of the study also demonstrated that productive disposition had the highest mean score (2.60), representing the greatest need for professional development. This result resonates with Shulman (2015), who addressed one of the limitations of pedagogical content knowledge (PCK), originally conceived as being devoid of emotion, feelings, and motivation. Based on the descriptive rubric provided with the questionnaire, these results show that teachers know little about productive disposition and cannot apply strategies toachieve it.

In particular, the results showed that teachers perceived a need to know how to enhance students' habitual inclination to see mathematics as sensible, useful, and worthwhile. Of similar importance was their interest in enhancing students' belief in their own efficacy, building positive attitudes towards mathematics, and enhancing student belief and diligence in learning mathematics.

This finding shows that productive disposition is the area of mathematics proficiency that requires the most attention for teachers. I suggest that one possible reason for this finding is that teaching as a profession has traditionally been concerned with instruction, but teachers themselves would like that to change; based 
on the findings, the first priority for teachers in this study was having mathematics make sense. This includes belief in the intrinsic value of mathematics, creating effective learners, and building positive attitudes and positive emotions towards mathematics learning. This is consistent with the work of Shriki and Lavy (2011), who addressed teachers' need for greater interaction with their students. Studies that further support these findings (Fang, 2012; Shriki \& Patkin, 2016) show that mathematics teachers need to build positive attitudes towards the learning of mathematics.

The findings of the study also indicated that the following needs were relevant to adaptive reasoning, with a mean score of 2.56. Mathematics teachers perceived needs for professional development in improving the following student skills: inductive reasoning, estimation and prediction, approximation, logical thinking, deductive reasoning, and mathematical thinking skills. Reflecting on their own activities, they focused on the following: modeling mathematical problems in daily life situations, enhancing mathematical proofs, and the teaching of mathematical patterns. This result reflects the perception that mathematics teachers see a need to develop higher-level thinking skills in their students. This may be because teachers found it difficult to enhance student capacity in engaging in logical thought, reflection, explanation, and justification. This result aligns with Shriki and Patkin (2016), who found that teachers should achieve basic teaching skills for developing students' capability to present mathematical arguments and justification and develop mathematical thinking skills and reflective abilities. Polly (2011) gives further support to this idea, demonstrating that there is a need for teachers to develop their students' adaptive reasoning skills, such as those demanding higher-level thinking. Fang (2012) addressed the need to enhance student ability to abstract or generalize mathematical ideas. Other researchers have cited the need to enhance the ability to overcome difficulties with mathematical proofing (Steele \& Rogers, 2012; Superfine \& Li, 2014).

Mathematics teachers' needs related to conceptual understanding were ranked in the middle for professional development, with a mean score of 2.49. They perceived a need to apply these specific strategies: teaching mathematical concepts, teaching to amend alternative concepts, teaching by using multiple mathematical representations, and measuring student acquisition of mathematical concepts. The results demonstrated teachers' needs relating to understanding how to teach mathematical concepts via problem solving and using conceptual maps in teaching mathematics. A need was identified for developing student ability in forming connections between relations in mathematics and making connections between mathematical concepts and procedures to reach conclusions. However, this sample of mathematics teachers perceived fairly relevant needs in identifying the mathematical concepts included in mathematical content, developing conceptual understanding for students, and developing student comprehension of mathematical operations. This result demonstrated that teachers have some knowledge of these areas yet limited experience in their application in the teaching of mathematics. This is consistent with other studies that addressed teachers' need to acquire different teaching skills or knowledge that may enhance students' conceptual understanding (Fang, 2012; Polly, 2011; Shriki \& Lavy, 2011; Superfine \& Li, 2014).

The fourth priority for mathematics teachers in this study was related to strategic competence, with a mean score of 2.45. This may refer to the type of strand centered more specifically on developing problemsolving skills within the curriculum. Most classes approached problem solving with relation to different topics specified in the curriculum; on the other hand, some classes addressed problem-solving strategies at the end of the unit. The results of the study demonstrated mathematics teachers' need to develop student ability in problem-solving and associated strategies as well as representing mathematical problems. Other studies have highlighted the need for teachers to master teaching skills that help their students develop their problem-solving skills (Fang, 2012; Evans, 2012; Evans, 2014; Superfine \& Li, 2014). However, teachers perceived fairly relevant needs in how to teach problem-solving techniques (steps). This may be because this skill is a mandatory part of the curriculum.

The results of the study showed that the lowest mean score was 2.45 , related to procedural fluency. This may reflect teachers practices in the mathematics classroom, where opportunities are given to develop student skills in carrying out mathematical procedures in a flexible, accurate, efficient, and appropriate way. This subsequently gives the students more chances to practice drill exercises, helping them develop mathematical algorithms and skills. 
Using the top 3 box scores to report and analyze the scale questions enabled the research findings to be more informative. Based on the descriptive rubric of the rating scale presented in the current study, the results offer more insights regarding teachers' needs in terms of specific knowledge and experience. The results also revealed the top six items representing the most essential perceived needs that were demonstrated by more than half of the respondents. In the "adaptive reasoning" domain, essential needs were "developing inductive reasoning for students" and "enhancing mathematical proof for students". For the "conceptual understanding" domain, the results showed that "using conceptual maps in teaching mathematics" and "teaching by using multiple mathematical representations" were also ranked within the top six perceived needs. The results also revealed additional essential needs for more than half of the respondents associated with the "procedural fluency" domain, including "enhancing students' procedural fluency in mathematical operations", and needs associated with the "productive disposition" domain, with perceived needs for "enhancing students' belief in diligence in learning mathematics". These results are sensitive and crucial to planning professional development programs and workshops that meet teachers' needs. For example, for better planning of Qatari teachers' professional development programs in the "productive disposition" domain, educators and mathematicians should be more aware regarding teachers' needs in "building positive attitudes towards mathematics", "enhancing students' habitual inclination to see mathematics as sensible, useful, and worthwhile", and "enhancing students' belief in one's own efficacy."

For the "conceptual understanding" domain, the results highlighted teachers' needs regarding knowledge and skills for "teaching to amend alternative concepts", "making connections between mathematical concepts and procedures to reach mathematical generalizations", and "applying specific strategies for teaching mathematical concepts". In addition, the results of the study underlined some teaching skills related to the "adaptive reasoning" domain, such as "developing logical thinking for students", "developing deductive reasoning for students", and "modeling mathematical problems in daily life situations".

The results of the study demonstrated that there were no statistically significant differences related to teachers' qualifications. This result could be explained by the majority of participating teachers having a bachelor's degree $(81.8 \%)$. This result is supported by Fang (2012), who found no effect on teachers' perceived needs due to their educational background. Despite this finding, using the top 3 box scores according to teachers' qualifications revealed that teachers with high qualifications perceive fewer professional development needs. This finding could be explained by the positive effect of continuous learning for teachers.

In addition, results of the study revealed no statistically significant differences linked to grade level taught. From the researcher's experience, one possible reason for this is that teachers at all levels may be supported by similar professional programs, with little concern for their needs or the grade level they teach. However, the research findings aligned with Shriki and Patkin (2016), who found minimal significance in perceived needs according to academic education or grade level taught. In addition, based on the results reported by the top 3 box scores regarding years of teaching experience in the current study, there are some differences regarding the percentages of the perceived professional development needs demonstrated by respondents of different groups in some domains. For example, primary teachers perceived more professional development needs for "developing inductive reasoning for students" and "using conceptual maps in teaching mathematics primary" compared to the other groups. This could be due to the type of the mathematical content taught in primary school, such as introducing primary mathematical concepts, and teachers' awareness in developing inductive reasoning for students in the early years.

One of the most interesting findings is that statistically significant differences were found with regard to years of teaching experience. Results found that teachers who have teaching experience from 4 to 6 years and from 7 to11 years perceived more professional development needs, with statistically significant differences compared with less-experienced colleagues (1-3 years) or even very experienced colleagues (more than 18 years). This was found across most strands of mathematical proficiency, with the exception of conceptual understanding, wherein the differences are statistically significant only for teachers with teaching experience of 4-6 years and no other groups. I suggest that this finding in general reflects that teachers in this period of experience are generally starting to identify their actual needs related to the SMP. The reason for the exception regarding teachers' needs related to conceptual understanding could explained because of this 
range of experience 4-6, where teachers become more aware of the importance of developing students' conceptual understanding, which requires less development time compared with other strands.

For teachers with less experience, this could be because of the type of undergraduate programs they completed, the content of which has helped them to acquire knowledge and skills that match new pedagogical trends in mathematics education to capture the SMP. On the other hand, this result may indicate a lack of awareness regarding the teachers' own professional development needs. In addition, results showed that teachers with more than 18 years of teaching experience perceived less need for professional development; this could be explained either by their rich experience in the field or because they have become less enthusiastic in participating in even more professional development programs.

\section{CONCLUSIONS}

This research instrument could also be developed to be used as a qualitative research tool to examine mathematics teachers' needs. this study investigated Jordanian mathematics teacher's perception of their professional needs Related to the five Strands of Mathematical Proficiency. the research instrument developed in this study demonstrated high validity and reliability across the Strands of Mathematical Proficiency. It is recommended that researchers use this research instrument in the field of mathematics education research to search for teachers' perceptions of their professional development needs. In addition, there is a need to develop qualitative research studies by conducting classroom observations or interviews for more in-depth research addressing the Strands of Mathematical Proficiency.

Accounting for a variety of variables such as qualifications, grade level taught, and number of years of experience, this study found professional development needs for mathematics teachers related to all five Strands of Mathematical Proficiency. This study demonstrated the need for and importance of conducting professional development programs for mathematics teachers that meet their needs. Teachers will be more enthusiastic about attending such tailored programs, which will maximize the impact on their development and may lead to effective ways of teaching. In turn, this will benefit student mastery of mathematics learning.

Based on the analysis in this study, the priority of professional development needs from the point of view of mathematics teachers demonstrated the need to provide teachers with professional development programs relevant to productive disposition, followed by adaptive reasoning, conceptual understanding, and strategic competence, and ended by procedural fluency consequently. It is recommended that teachers be provided with professional developmental programs based on these priorities. The results offer more insight into mathematics teachers' most essential needs in terms of specific knowledge and experience within different categories. This information aids in planning professional development programs and workshops that will meet teachers' needs. Some results were not expected, such as there being no significant differences found with regards to grade level taught and teacher qualifications. More in-depth qualitative research is recommended to identify the effect of such factors.

One interesting finding in this study is that the number of years of experience for mathematics teachers resulted in different needs, where teachers with fewer years of experience perceived fewer needs compared with more experienced colleagues. More research is recommended to examine whether this result is due to the type of undergraduate programs teachers have attended. In particular, there should be a focus on whether their undergraduate programs helped them to acquire knowledge and skills that match new trends in mathematics education to capture the SMP, or if they simply have a relative lack of awareness of their professional development needs.

\section{REFERENCES}

Acara (2014). Australian curriculum: Senior secondary mathematics, general mathematics (rationale/aims). Retrieved from http://australian

curriculum.org/seniorsecondary/mathematics/generalmathematics/rationaleaims

Anshori,I. \& Suwidiyanti (2020). Improvement of mathematics teacher performance through academic supervision with collaborative approaches. International Journal of Educational Research Review,4(3),227-242. 
Barham, A., \& Al-Khateeb, M. (2012). Students' levels in the mathematical thinking skills for classroom teachers at the Hashemite University and its relation to their achievement in mathematics. The Educational Journal, 26(103), 277-312.

Bencherab,A. \& Maskari,A.A. (2021). Clinical supervision: A genius tool for teachers' professional growth. The Universal Academic Research Journal,3(2),51-57.

Bednarz, N., Fiorentini, D., \& Huang, R. (2011). International approaches to professional development of mathematics teachers. Ottawa: University of Ottawa Press.

Conference Board of the Mathematical Sciences. (2012). The mathematical education of teachers II. Providence, RI: American Mathematical Society and Mathematical Association of America.

Council of Chief State School Initiatives (CCSSI). (2010). Common core state standards for mathematics. Washington, DC: Council Chief State Officers.

Creswell, J. W. (2014). Research design: Qualitative, quantitative and mixed methods approaches. London: Sage Publications Ltd.

Davis, B. \& Simmt, E. (2006). Mathematics-for-teaching: An ongoing investigation of mathematics that teachers (need to) know. Educational Studies in Mathematics, 61(3), 293-319. https://doi.org/ 10.1007/s10649006-2372-4

Evans, B. R. (2012). Editor's perspective article: Problem solving abilities and perceptions in alternative certification mathematics teachers. JNAAC, 7(2), 34-43.

Evans, B. R. (2014). Editor's perspective article: Mathematics and science teaching for new alternative certificate teachers. JNAAC, 9(2), 44-48.

Gürer, G. (2019). The opinions of pre-school teachers about students' aggressive behavior. The Universal Academic Research Journal, 1(1), 42-52.

Fang, Q. (2012). A study on high school mathematics teachers' mathematics professional literacy: What does high quality mathematics teaching need? Journal of Mathematics Education, 5(1), 136-158.

Fuson, K. C. (1990). Conceptual structures for multiunit numbers: Implications for learning and teaching multidigit addition, subtraction, and place value. Cognition and Instruction, 7(4), 343-403. https://doi.org/10.1207/s1532690xci0704_4

General Secretariat for Development Planning (2008). Qatar National Vision 2030. Doha: GSDP.

Hariyani,S. Ahmad,N.J.\& Marsitin,R. (2021). Mathematics teaching practicum for junior high school in a different culture-based situation. The Universal Academic Research Journal,3(2),77-86.

Hiebert, J., Carpenter, Fennema, E., Fuson, Wearne,Human, P. (1997). Making sense: Teaching and learning mathematics with understanding. Portsmouth, NH: Heinemann. 
Hill, H., \& Ball, D. (2004). Learning mathematics for teaching: Results from California's mathematics professional development institutes. Journal for Research in Mathematics Education, 35(5), 330-351. https://doi.org/10.2307/30034819

Kaiser, G., Blömeke, S., König, J., Busse, A., Döhrmann, M., \& Hoth, G. (2017). Professional competencies of (prospective) mathematics teachers-Cognitive versus situated approaches. Educational Studies in Mathematics, 94(2), 161-182. https://doi.org/ 10.1007/s10649-016-9713-8

Loucks-Horsley, S., \& Matsumoto, C. (1999). Research on professional development for teachers of mathematics and science: The state of the scene. School Science and Mathematics, 99(5), 258-271. https://doi.org/10.1111/j.1949-8594.1999.tb17484.x

Mundry, S. (2005). What experience has taught us about professional development. National Network of Eisenhower Regional Consortia and Clearinghouse Network. Retrieved from http://citeseerx.ist.psu. edu/viewdoc/download?doi=10.1.1.520.4079\&rep=rep1\&type=pdf

National Center for Education Statistics (2012). Highlights from TIMSS 2011. Mathematics and science achievement of U.S. fourth- and eighth-grade students in an international context. Washington, DC: U.S. Department of Education.

National Center for Education Statistics (2016). Highlights from TIMSS 2015. Mathematics and science achievement of U.S. fourth- and eighth-grade students in an international context. Washington, DC: U.S. Department of Education.

National Council of Teachers of Mathematics (2000). Principles and standards for school mathematics. Reston, VA: NCTM.

National Research Council (2001). Adding it up: Helping children learn mathematics. Washington, DC: The National Academies Press.

National Staff Development Council (1995). National staff development council's standards for staff development. Oxford, OH: National Staff Development Council.

Pisa (2012). The Guardian. Retrieved from https://www.theguardian.com/news/ datablog/2013/dec/03/pisaresults-country-best-reading-maths-science

Polly, D. (2011). Examining teachers' enactment of technological pedagogical and content knowledge (TPACK) in their mathematics teaching after technology integration professional development. Journal of Computers in Mathematics and Science Teaching, 30(1), 37-59.

Robinson, J., Shaver, P., \& Wrightsman, L. (1991). Criteria for scale selection and evaluation in measures of personality and social psychological attitudes. New York: Academic Press. https://doi.org/10.1016/ B978-0-12590241-0.50005-8

Rowan, B., Correnti, R., \& Miller, R. J. (2002). What large-scale survey research tells us about teacher effects on student achievement: Insights from the prospects study of elementary schools. Teachers College Record, 104, 1525-1567. https://doi.org/ 10.1111/1467-9620.00212

Schoenfeld, A. H. (1988). Problem solving in context(s). In R. I. Charles, \& E. A. Silver (Eds.), The teaching and assessing of mathematical problem solving (Research Agenda for Mathematics Education, Vol. 3, pp. 82-92). Reston, VA: National Council of Teachers of Mathematics. 
SEC [Supreme Education Council] (2014). Education and training sector strategy 2011-2016: Executive summary. Doha: SEC Press.

Shriki, A., \& Lavy, I. (2011). Perceptions of Israeli mathematics teachers regarding their professional development needs. Professional Development in Education, 38(3), 411-433. https://doi.org/10.1080/ 19415257.2011.626062

Shriki, A., \& Patkin, D. (2016). Elementary school mathematics teachers' perception of their professional needs. Teacher Development, 20(3), 329-347. https://doi.org/10.1080/13664530.2016.1155476

Shulman, L. S. (1987). Knowledge and teaching: Foundations of the new reform. Harvard Educational Review, 57(1), 1-22. https://doi.org/10.17763/ haer.57.1.j463w79r56455411

Shulman, L. S. (2015). PCK: Its genesis and exodus. In A. Berry, P. Friedrichsen, \& J. Loughran (Eds.), Reexamining pedagogical content knowledge in science education (pp. 13-23). New York: Routledge.

Steele, M. D., \& Rogers, K. C. (2012). Relationship between mathematical knowledge for teaching and teaching practice: The case of proof. Journal of Mathematics Teacher Education, 15(2), 159-180. https://doi.org/10.1007/s10857-012-9204-5

Superfine, A. C., \& Li, W. (2014). Developing mathematical knowledge for teaching teachers development of teacher educators. Issues in Teacher Education, 23(1), 113-132.

Villegas-Reimers, E. (2003). Teacher professional development: An international review of the literature. UNESCO: International Institution for Educational Planning.

Vural,Ö.F. \& Vural,S. (2021). An examination of 5th grade mathematics curriculum in terms of 21st century skills. International Journal of Educational Research Review,6(2),82-92.

Wood,L.N.,Vu,T., Bower,M.,Brown,N., Skalicky, J., Donovan,D.,Birgit,L.,Jpshi,L. \& Bloom, W. (2011). Professional development for teaching in higher education. International Journal of Mathematical Education in Science and Technology, 42(7), 997-1009. https://doi.org/10.1080/0020739X.2011.608864 